This is the accepted manuscript of the article, which has been published in Hamada R., Soranastaporn S., Kanegae H., Dumrongrojwatthana P., Chaisanit S., Rizzi P. \& Dumblekar V. (eds) Neo-Simulation and Gaming Toward Active Learning. Singapore: Springer. Translational Systems Sciences vol. 18. ISBN: 978-981-13-8038-9. ISSN: 2197-8832.

https://doi.org/10.1007/978-981-13-8039-6_51

\title{
Chapter X:
}

\section{Educational Gamification: Challenges to Overcome - and to Enjoy}

\author{
J. Tuomas Harviainen ${ }^{1}$, Mikko Meriläinen ${ }^{1}$ \\ ${ }^{1}$ Tampere University, Finland
}

\begin{abstract}
This paper presents a critical viewpoint on educational gamification, an understudied field filled with hyperbole and hollow sales pitches, as well as solid research. By reviewing existing research in the context of Landers' Theory of Gamified Learning, it discusses three underlying, important elements that need to be taken into account: engagement, challenge, and reflection, as well as the interconnections between them. As a result, it suggests ways for more efficient deployment of gamification for educational purposes.
\end{abstract}

Keywords: Educational gaming; Gamification; Learning; Reflection.

\section{Introduction}

Gamification is still gaining traction in educational contexts, both in schools and in business organizations, even as its veracity receives more critical analysis [1]. Applications include both the gamification of education and the gamification of learning, two things that are not the same. On the one hand, we can gamify the tools and processes that are used for learning and on the other, people may gamify the processes they use to learn. In many cases, those two correspond, but not always. As things stand now, quite a lot is known about educational gaming, but much less about the use of game elements for learning in non game-tasks. This paper looks at the current evidence and suggests ways for applying educational gamification in an effective manner. As noted by Harviainen [2], much of the current theory development in gamification of educational contexts relies on conjecture and 
extrapolation. To put it bluntly: we have great examples of it working, but know little of why it actually works. This is a fact spotted decades ago already [3], but left unsolved. In the last four years since a similar claim was again made by Harviainen, Lainema and Saarinen [4], it appears little has changed in that regard. This is no surprise, since we keep also getting similar statements about educational gaming, and have been for decades (e.g., [5]).

In a rare exception Landers [6] (see Figure 1), based on Deterding et al. [7] and Bedwell et al. [8], formed a theory of gamified learning, in which gamification is defined as "the use of game attributes, as defined by the Bedwell taxonomy, outside the context of a game with the purpose of affecting learning-related behaviors or attitudes". This is an important focus. As noted above, gamification can be applied for different purposes and in differing parts of the learning process, and those affect different factors that influence learning. Changing behavior is not the same as changing attitudes.

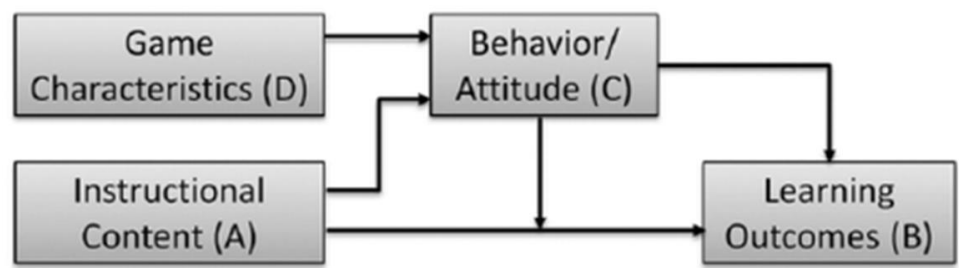

Fig. 1. Theory of gamified learning [6].

In the following sections, we examine some of the key attributes, but ones distinct from those of Landers and Bedwell et al. Our focus is on understanding prerequirements, rather than on singular attributes that contribute to learning. We concentrate on three points: engagement, challenge, and reflection.

\section{The Role of Engagement}

Engagement is necessary for learning, but how much engagement - or immersion - is optimal? Without engagement, the activity remains uninteresting, which prohibits learning [9]. With too much engagement, reflection may be lost [10]. What makes gamified activities more complex in this sense is that since there is no singular game to play, but rather goal-oriented real-life activities that have had game elements added to them, the potential for distractions is much higher. So is also the risk of the "chocolate covered broccoli" -effect, in which an educational purpose is just sugar-coated with play, the entertainment value of which may well be rather passing. When the players start considering the whole thing an annoyance hidden behind a bit of temporary fun, novelty will wear off (as per [11]) and the activity will be found even less interesting than it would have been without the gamification.

Engagement is elusive, in that it can sometimes be achieved by simply framing an activity as a game [12]. Other designers turn to much deeper tools (e.g., [13]), and 
when the entire activity is also storified through a shared narrative [14], engagement usually increases. Yet engagement is like hermeneutic pre-understanding: it is what makes the play meaningful, and the immediate feedback received valuable for the participants, but it also inevitably creates biased responses. Furthermore, not everyone likes to play for achievements [15], or to play games at all [16], so the classic gamification tools of "points, badges and leaderboards" may be insufficient.

It is tempting, especially for classroom environments, to just form a pretense framework around a learning content. This is particularly true for one of the oldest gamification techniques, role-playing. By adding the component of roles to tasks, interest can indeed be increased [17]; [18]. For certain topics (e.g., language learning; [19]; [20]) it works well, for others it is just chocolate on that broccoli. With learning tasks and roles (or narratives) too far apart, connections become meaningless and the play becomes uninteresting [21].

\section{The Role of Challenge Level}

Another factor that comes out in research time and again as significantly influencing learning is challenge level (e.g., [10]; [22]; [23]). Too difficult challenges create boredom, but likewise insufficient challenge makes people lose interest [24]. This factor therefore ties directly into the previous one, engagement. Optimal challenge creates engagement, possibly even flow, which in turn connects to learning [23].

Gamified challenges are problems, and thus lead to problem-based learning with authentic activity (as per [25]). It is therefore not at all without significance, what kinds of gamification elements are used. The tasks need to be meaningful, educational and interesting at the same time. Especially important is that the challenges clearly relate to the intended learning task. It is not just a question of creating motivation through engagement, but also an issue of achieving the desired educational goals. Incidental "stealth" learning cannot be trusted [16], and if a participant is highly competitive, they may learn completely wrong things while trying to win (or "win") the gamified activity [4]; [26].

Challenge is, quite frankly put, very difficult to achieve in an educational game or gamified situation. In even recreational games, optimizing gameplay-related skill learning curves is hard. In an educational game or gamified activity, to that equation is added the knowledge level of each player, which in even a single classroom or business school course can hugely vary. Optimized the right way, people can be enticed to transcend their self-set limitations (e.g., a student daring to start speaking broken English, carried away by the desire to win an argument in a role-play [20]). In other cases, pre-existing differences in competencies just lead some players to frustration and others to boredom. And with either situation, the learning curve probably vanishes. 


\section{The Role of Reflection}

As with serious games, successful educational gamification furthermore requires reflection (see [4]). If the gamification is able to increase reflection above the level on which it would otherwise be (through e.g., time-on-task or gamified notekeeping), learning is likely to be improved even further [6]. Excluding certain specific game types (see [27]; [28]), reflection needs to be handled outside of play [4]. This is why simulation/gaming has so strongly focused on emphasizing highquality debriefing [29]. If the participants have problematic attitudes, however, even a great debriefing will not help [30].

Reflection is difficult to embed directly into play, but not impossible. In contrast to games, gamification has the advantage that it is directly tied into real-world elements, instead of being a simulation or simplification of them (as per [31]; [32]). Problems can therefore be built around the actual skills needed, issues resolved, and learning goals to be attained. This does not remove all of the risks of the learning remaining context-bound (see [30]), but strongly lessens the likelihood of that happening. This is especially important, if the gamification is meant to produce learning on an organizational level [33]. It is furthermore possible to embed moments of reflection into the activity itself, in a manner similar to the use of design games (see [27]). If that reflection can be placed in sequence with logically structured play elements (as per [24]), all the better. Nevertheless, here too Knotts and Keys' [34] observation that performance in an educational game does not equate learning, rings true. At least we can make the two correlate better, through careful gamification, nowadays.

\section{Discussion and Conclusions}

The challenge in this combination is that it does not actually work. Optimal challenge is known to create high engagement [23], which is a detriment to the reflection necessary for learning something out of the play, rather than learning to just play that particular system [4]. With insufficient engagement, whether from a lack of good challenge or due to a lack of interesting content, the play remains boring, and thus not interesting to reflect upon (see Figure 2). It is thus up to the designers to make sure that the gamified elements are optimized for this purpose, and that even as the initial novelty effect of gamification may wear off or even turn against its original purpose [11], the challenge continues being balanced and the engagement level remains enticing but not too strong. Games are able to do this [23], but for gamification it is much harder. 


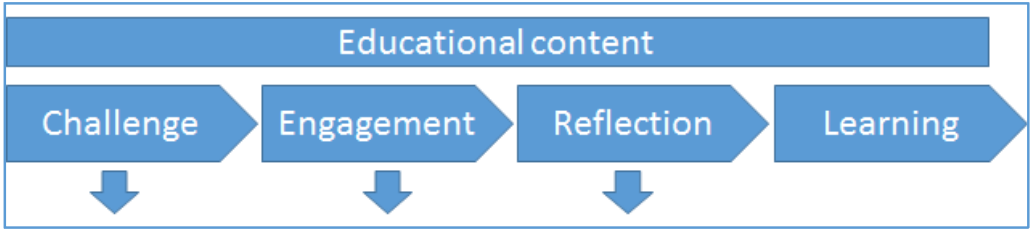

Fig. 2. The three factors, with risk of deviation in each, and the mandatory presence of instructional, educational content at all points.

All of these factors are necessary, but they are complementary to the main goal. As Landers [6] notes, "The goal of gamification cannot be to replace instruction, but instead to improve it." The instructional content needs to be able to facilitate learning on its own, or gamification cannot help. Likewise, without paying attention to the three factors discussed in this paper, however, instead of improvement we will have just hindrances. If they work, players will be able to absorb the educational goals into their intrinsic motivations (as per [35]), and then it is up to tailoring the other elements (as per [6]) in line, to facilitate maximal learning potential. If they do not, play becomes a distraction from learning, rather than its advocate [16].

Gamified education often lacks one of the key advantages of serious games and other novel learning environments: the ability to experiment and fail safely. That ability has for example been seen as a key element in fostering innovation and creativity [36]; [37] in studies discussing learning in game jams, a type of free-form game creation event. As a result, some of the knowledge of how educational games and novel, informal learning environments function cannot be directly applied to educational gamification.

This suggests that a key avenue of approach may be the exploration of playful mindsets and play states and their cultivation. Rather than concretely making learning into a game, by including an element of competition or rewards, for example, we can instead seek to cultivate some of the intangible things people enjoy in games and play, such as fun and creativity. Environments such as educational institutions or workplaces are often built around competition, goals and rewards, either advertently or inadvertently, and care must be taken that gamification does not become a simple cosmetic makeover of this. The assumption of a playful mindstate is a fundamental shift from more traditional means of learning: the focus is less on the product and more on the process [38], with an emphasis on imagination, creativity and collaboration [39]. The concept of "playification" has been suggested to either replace or extend beyond reward-based gamification [40]; [41]. At the very least, it is an important, interconnected side of the same proverbial coin [14].

We therefore recommend that educational gamification should seek out a balance between engagement (which usually but not always may mean "fun" [42]) and reflection, feature a smooth task-based learning curve interspersed by short moments of fruitful reflection, have a challenge level that increases while teaching the skills and knowledge needed to enjoy the increases, and enough room for experimentation that also some new positive effects may emerge. A playful 
approach emphasizing fun, creativity and collaboration over tasks, rewards and competition may help overcome some of the challenges discussed in this paper. Gamification has been shown to work for improving positive behavior better than other forms of motivational increasing [43], so it is logical that we also examine its educational applications further.

Promoting active learning and engaging learners is not a trivial task, and both has been and continues to be a key issue in both the science and practice of education. The learning process is always a complex interplay of situational and personal variables, and no pedagogical method guarantees that intended learning takes place (e.g., [44]). As a result, novel approaches to education will inevitably succeed in some areas and situations and fail in others. Instead of seeking to conclude whether a method categorically works or not, the focus should be on leveraging its strengths and avoiding its weaknesses while evaluating the method's suitability for achieving set goals and making notes of encountered problems.

Gamification is an imprecise tool, but despite its flaws, it is able to offer much to making learning more motivating, more effective. The aforementioned challenges should be seen as inspiring, enjoyable constraints, not as limitations. The use of gamification in educational context, in our opinion, forces educators to re-evaluate their subject matter and pedagogical methods, in order to gamify that matter. If it does not seem possible to gamify it, something must yield - not everything is learned best in a playful manner. Likewise, the learning of the right things cannot be guaranteed, in gamification, so the process also requires an examination of the methods used for debriefing and anchoring the desired results. Further research should therefore conducted in this area, to find out which tools fit which subject matter, and which parts of which curricula would benefit from being gamified.

\section{References}

1. Landers RN, Auer EM, Collmus AB, Armstrong MB (2018) Gamification science, its history and future: Definitions and a research agenda. Simulat Gaming 49:315-337.

2. Harviainen, JT (2014) Critical challenges to gamifying education: a review of central concepts. In: Vorobyov AV (ed) Digest of the international conference on digital game-based learning Game ON! Moscow.

3. Kibbee JM, Craft CJ, Nanus B (1961) Management games: a new technique for executive development. Reinhold, New York.

4. Harviainen JT, Lainema T, Saarinen E (2014) Player-reported impediments to game-based learning. T Dig Games Res Assoc 1:55-83.

5. Keys B, Wolfe J (1990) The role of management games and simulations in education and research. J Manage 16:307-336.

6. Landers, $\mathrm{RN}$ (2014) Developing a theory of gamified learning: linking serious games and gamification of learning. Simulat Gaming 45:752-768. 
7. Deterding S, Sicart M., Nacke L, O'Hara K., Dixon D (2011) Gamification: toward a definition. In: Proceedings of the CHI 2011 gamification workshop, Vancouver, British Columbia, Canada.

8. Bedwell WL, Pavlas D, Heyne K, Lazzara EH, Salas E (2012) Toward a taxonomy linking game attributes to learning: an empirical study. Simulat Gaming 43:729-760.

9. Balzer M (2011) Immersion as a prerequisite of the didactical potential of roleplaying. Int J Role-Play 2:32-43.

10. Henriksen TD (2008) Extending experiences of learning games - or why learning games should be neither fun, educational or realistic. In: Leino O, Wirman H, Fernandez A (eds) Extending experiences. University of Lapland, Rovaniemi, pp 140-162.

11. Koivisto J, Hamari J (2014) Demographic differences in perceived benefits from gamification. Comput Hum Behav 35:179-188.

12. Lieberoth A (2015) Shallow gamification: testing psychological effects of framing an activity as a game. Games Cult 10:229-248.

13. Seaborn K, Fels DI (2015) Gamification in theory and action: a survey. Int $\mathbf{J}$ Hum-Comp St 74:14-31.

14. Deterding S (2016) Make-believe in gameful and playful design. In: Turner P, Harviainen JT (eds) Digital make-believe. Springer, Basel, pp 101-214.

15. Warmelink H (2014) Online gaming and playful organization. Routledge, New York.

16. Whitton $\mathrm{N}$ (2014) Learning with digital games: a practical guide to engaging students in higher education. Routledge, New York.

17. Crookall D, Oxford R, Saunders D (1987) Towards a reconceptualization of simulation: from representation to reality. Simul Games Learn 17:147-171.

18. Hyltoft M (2010) Four reasons why edu-larp works. In: Dombrowski K (ed) LARP: Einblicke. Zauberfeder, Braunschweig, pp 43-57.

19. Cruaud C (2018) The playful frame design and use of a gamified application for foreign language learning. University of Oslo, Oslo.

20. Harviainen JT, Savonsaari R (2013) Larps in high schools. In: Moseley A, Whitton N (eds) New traditional games for learning, pp 134-145. Routledge, London, pp 134-145.

21. Schrier K (2016) Knowledge games: how playing games can solve problems, create insight, and make change. Johns Hopkins University Press, Baltimore.

22. Carlson JGH, Misshauk MJ (1972) Introduction to gaming: management decision simulations. Wiley, New York.

23. Hamari J, Shernoff DJ, Rowe E, Coller B, Asbell-Clarke J, Edwards T (2016) Challenging games help students learn: an empirical study on engagement, flow and immersion in game-based learning. Comput Hum Behav 54:170 179.

24. Graham RG, Gray CF (1969) Business games handbook. American Management Association, USA. 
25. Duffy TM, Cunningham DJ (1996) Constructivism: implications for the design and delivery of instruction. In: Jonassen DH (ed) Handbook of research for educational communications and technology. Macmillan, New York, pp 170-198.

26. Hakulinen L, Auvinen T, Korhonen A (2013) Empirical study on the effect of achievement badges in TRAKLA2 online learning environment. In: Proceedings of learning and teaching in computing and engineering (LaTiCE) conference, March 21-24, 2013, Macau, pp 47-54.

27. Hannula O, Harviainen JT (2016) Efficiently inefficient: service design games as innovation tools. In Morelli N, de Götzen A, Grani F (eds) Service design geographies: proceedings of the servdes 2016 conference, May 24-26, 2016, Copenhagen, Denmark, pp 241-252.

28. Hannula O, Harviainen JT (2018) User perceptions of design games as settings for organizational learning: case Topaasia Cards. In: Proceedings of the servdes 2018 conference, June 18-20, Milan, Italy.

29. Crookall D (2010) Serious games, debriefing, and simulation/gaming as a discipline. Simulat Gaming 41:898-920.

30. Kim DH (1993) The link between individual and organizational learning. Sloan Manage Rev 35:37-50.

31. Linderoth J (2011) Why gamers don't learn more: an ecological approach to games as learning Environments. J Gaming Virt Worlds 4:45-62.

32. Thavikulwat $P$ (2004) The architecture of computerized business gaming simulations. Simulat Gaming 35:242-269.

33. Vesa M, Hamari J, Harviainen JT, Warmelink H (2017) Computer games and organization studies. Organ Stud 38:273-284.

34. Knotts US Jr, Keys JB (1997) Teaching strategic management with a business game. Simulat Gaming 28:377-394.

35. Deci EL, Ryan RM (2002) Overview of self-determination theory: an organismic dialectical perspective. In: Handbook of self-determination Research, pp 3-33.

36. Arya A, Chastine J, Preston J, Fowler A (2013) An international study on learning and process choices in the global game jam. Int J Game-B Learn 3:27-46.

37. Guevara-Villalobos O (2011) Cultures of independent game production: examining the relationship between community and labour. In: Proceedings of the digital games research association (DiGRA) conference: think design play, September 14-17, 2011, Hilversum.

38. Grace L (2016) Deciphering hackathons and game jams through play. In: Proceedings of the international conference on game jams, hackathons, and game creation events, March 13, 2016, San Francisco, pp 42-45.

39. Kangas M (2010) Creative and playful learning: learning through game cocreation and games in a playful learning environment. Think Skills Creat 5:115. 
40. Nicholson S (2015) A RECIPE for meaningful gamification. In: Reiners T, Wood L (eds) Gamification in education and business. Springer, Cham, pp 120 .

41. Segura EM, Waern A, Segura LM, Recio DL (2016) Playification: the physeear case. In: Proceedings of the 2016 annual symposium on computerhuman interaction in play, October 16-19, 2016, Austin, pp 376-388.

42. Vahlo J (2018) In gameplay: the invariant structures and varieties of the video game gameplay experience. University of Turku, Turku.

43. Lieberoth A, Jensen NH, Bredahl T (2018) Selective psychological effects of nudging, gamification and rational information in converting commuters from cars to buses: a controlled field experiment. Transp Res F 55:246-261.

44. Kirschner PA, Sweller J, Clark RE (2006) Why minimal guidance during instruction does not work: an analysis of the failure of constructivist, discovery, problem-based, experiential, and inquiry-based teaching. Educ Psychol 41:75-86.

\section{Author bios}

J. Tuomas Harviainen is Professor of Information Studies at the Tampere University, Finland, an ISAGA Advisory Council member, and one of the editors of the journal Simulation \& Gaming. His work has been published in venues such as Organization Studies, New Media \& Society, Journal of Business Ethics, and Journal of Documentation.

Mikko Meriläinen is a game education researcher at Tampere University, Finland. His work currently focuses on studying and developing game jamming, a process of rapid, timeconstrained game creation, as a learning tool. 